University of Nebraska - Lincoln

DigitalCommons@University of Nebraska - Lincoln

\title{
Occurrence of the Waxy Alleles wxa and wxb in Waxy Sorghum Plant Introductions and Their Effect on Starch Thermal Properties
}

Jeffrey F. Pedersen

USDA-ARS NPA Grain, Forage \& Bioenergy Research, jpedersen1@unl.edu

Robert A. Graybosch

University of Nebraska-Lincoln, bob.graybosch@ars.usda.gov

D. L. Funnell

USDA-ARS NPA Grain, Forage \& Bioenergy Research

Follow this and additional works at: https://digitalcommons.unl.edu/usdaarsfacpub

Part of the Agricultural Science Commons

Pedersen, Jeffrey F.; Graybosch, Robert A.; and Funnell, D. L., "Occurrence of the Waxy Alleles wxa and $w x b$ in Waxy Sorghum Plant Introductions and Their Effect on Starch Thermal Properties" (2007). Publications from USDA-ARS / UNL Faculty. 913.

https://digitalcommons.unl.edu/usdaarsfacpub/913

This Article is brought to you for free and open access by the U.S. Department of Agriculture: Agricultural Research Service, Lincoln, Nebraska at DigitalCommons@University of Nebraska - Lincoln. It has been accepted for inclusion in Publications from USDA-ARS / UNL Faculty by an authorized administrator of DigitalCommons@University of Nebraska - Lincoln. 


\title{
Occurrence of the Waxy Alleles $w x^{a}$ and $w x^{b}$ in Waxy Sorghum Plant Introductions and Their Effect on Starch Thermal Properties
}

\author{
J. F. Pedersen,^ R. A. Graybosch, and D. L. Funnell
}

\begin{abstract}
The existence of two waxy alleles, $w x^{a}$ associated with no detectable granule bound starch synthase (GBSS) and $w x^{b}$ associated with apparently inactive GBSS, was recently reported in sorghum [Sorghum bicolor (L.) Moench]. In this paper, the occurrence of the $w x^{a}$ and $w x^{b}$ alleles in the USDA-ARS photoperiod-insensitive sorghum collection was determined, and the effects of the $w x^{a}$ and $w x^{b}$ alleles on thermal properties of sorghum starch (gelatinization temperatures and energy requirements) measured by differential scanning calorimetry. Of the 51 purported waxy accessions examined, 14 tested positive for presence of amylose by iodine staining and were considered to be previously misclassified wildtype lines. Nine accessions were mixed for presence or absence of amylose. Twenty-four of the 28 accessions confirmed to be waxy by negative iodine staining for amylose had no detectable GBSS using sodium dodecyl sulfate polyacrylamide gel electrophoresis (SDS-PAGE) $\left(w x^{2}\right)$, and four were show to contain GBSS $\left(w x^{b}\right)$. Mean gelatinization onset, peak, and end temperatures were significantly lower for wild-type than either of the two waxy genotypes. Mean gelatinization onset temperature was slightly higher for waxy-GBSS+ genotypes than waxy-GBSSgenotypes. Mean gelatinization end temperature was slightly higher for waxy-GBSS- genotypes than waxy-GBSS+ genotypes. Significant genetic variation was observed within genotypic classes, suggesting influence of additional modifier genes affecting sorghum starch structure or micro-environmental effects.
\end{abstract}

USDA-ARS Grain, Forages and Bioenergy Research, Univ. of Nebraska, Lincoln, NE 68583-0937. Joint contribution of the USDAARS and the Univ. of Nebraska Agric. Exp. Stn. The use of trade, firm, or corporation names in this publication is for the information and convenience of the reader. Such use does not constitute an official endorsement or approval by the USDA or the ARS of any product or service to the exclusion of others that may be suitable. Received 11 Oct. 2006. ^Corresponding author (Jeff.Pedersen@ars.usda.gov).

Abbreviations: DSC, differential scanning calorimeter; GBSS, granule bound starch synthase; PI, plant introduction; QTL, quantitative trait locus; SDS-PAGE, sodium dodecyl sulfate polyacrylamide gel electrophoresis.

S ORGHums [Sorghum bicolor (L.) Moench] with modified starch are receiving increased attention as the sorghum industry explores new food and industrial uses for its grain. The waxy phenotype has been recognized in sorghum since 1933 (Karper, 1933) and is associated with endosperm starch lacking amylose and composed of nearly $100 \%$ amylopectin. In cereals, this condition is usually due to a lack of functionality of the amylose-forming enzyme granule bound starch synthase (GBSS; EC 2.4.1.242).

Presence or absence of amylose has significant impact on the physicochemical properties of starch. Amylose can form a firm gel, while amylopectin exhibits low syneresis and high resistance to retrogradation (Takahiro et al., 2003). Amylose molecules tend to predominate in amorphous regions of starch granules. Crystalline regions are dominated by amylopectin, with the degree of crystallinity thought to be a function of the branch frequency, and branch length, of amylopectin (Martin and Smith, 1995). However, differences in physicochemical properties of starches from waxy vs. wild-type grains at the species level have been documented. Jane

Published in Crop Sci. 47:1927-1933 (2007)

doi: 10.2135/cropsci2006.10.0652

(C) Crop Science Society of America

677 S. Segoe Rd., Madison, WI 53711 USA

All rights reserved. No part of this periodical may be reproduced or transmitted in any form or by any means, electronic or mechanical, including photocopying, recording, or any information storage and retrieval system, without permission in writing from the publisher. Permission for printing and for reprinting the material contained herein has been obtained by the publisher. 
et al. (1999) reported starches from waxy rice (Oryza sativa L.) with low retrogradation rates compared to starch from wild-type rice, while retrogradation rates of starch from waxy maize (Zea mays L.) were similar to starch from wildtype maize. More recent research on rice has shown physicochemical differences among low amylose lines within the species (Takahiro et al., 2003).

As in many other cereals, sorghum was recently shown to have variants at the waxy loci. In a set of eight waxy sorghum lines, Pedersen et al. (2005) discovered the existence of two waxy alleles, $w x^{a}$ and $w x^{b}$. Waxy lines with allele $w x^{a}$ produce no detectable GBSS. In waxy lines carrying the waxy allele $w x^{b}$, GBSS is produced, detectable by both gel electrophoresis and immunoblotting, but it is evidently nonfunctional. With respect to GBSS production, the allele $w x^{a}$ is recessive to $w x^{b}$, and, and with respect to amylose synthesis, both waxy alleles are recessive to the wild-type, $W x$. Only two of the eight lines had the $w x^{b}$ allele, and both were reported to share a common pedigree (Pedersen et al., 2005). The frequency and distribution amongst sorghum germplasm of the two $w x$ alleles, and their effects on starch thermal properties, is unknown.

One method of describing physicochemical and thermal properties of starches is the differential scanning calorimeter (DSC). This method has become "the method of choice for studying starch gelatinization phenomena" and measures the difference in enthalpy change that occurs during gelatinization of starch samples (Lund, 1984, p. 254). These gelatinization phenomena have impact on cooking, textural properties, digestibility, and an array of other characteristics impacting the food industry. Numerous studies, especially with maize starch, have employed DSC as a means of assessing both genetic and environmental factors conditioning starch variation. White et al. (1990) detected significant variation in DSC gelatinization onset and peak temperatures, both within and across open pollinated maize populations. Sanders et al. (1990) used DSC to characterize maize starches derived from lines carrying one or more of the endosperm mutants $w x$, $a, s u$, and $d u$. Differential scanning calorimeter onset and peak gelatinization temperatures of the mutants and of lines carrying various combinations of mutations differed from each other and from wild-type. Scott and Duvick (2005) studied the distribution of quantitative trait loci (QTLs) controlling starch variation, as detected by DSC. They found one such QTL to cosegregate with the maize Wx1 locus, known to control GBSS synthesis.

Relative to maize, comparatively little is known of genetic variation for starch properties in sorghum. The USDA-ARS photoperiod-insensitive sorghum germplasm collection (http://www.ars-grin.gov/npgs/) contains 53 accessions that have been identified as waxy. The following study was therefore designed to determine the occurrence of the $w x^{a}$ and $w x^{b}$ alleles in this genetically diverse set of sorghum lines, to determine the effects of the $w x^{a}$ and $w x^{b}$ alleles on thermal properties of sorghum starch as measured by DSC, and to determine whether genetic variation exists in properties of sorghum starch within $w x^{a}$ and $w x^{b}$ genotypic groups.

\section{MATERIALS AND METHODS}

Fifty-three Plant Introductions (PIs) identified as waxy from the USDA-ARS photoperiod-insensitive sorghum collection were obtained from the USDA-ARS Southern Regional Plant Introduction Station, Griffin, GA (http://www.ars-grin.gov/ npgs/). Accession number, local name, and country of origin are shown in Table 1. Seed quantities of 51 of these lines (two did not set seed before frost) were increased by self-pollination under bags in 2002. PI 562768 produced a mixture of red and white seed. PI 455543 produced a mixture of white and brown seed, but only the white seed reached maturity.

The 51 accessions; 'Ellis', a waxy control; and nine wildtype controls ('Atlas', 'Brawley', 'Dale', E35-1, IS2261, 'Kansas Collier', N98, 'Rox Orange', and 'Wray') were planted in replicated field trials in 2003 and 2004 at the University of Nebraska Field Laboratory, Ithaca, NE (Sharpsburg silty clay loam; fine, smectitic, mesic Typic Argiudoll). Plots consisted of single 7.6-m rows spaced $76 \mathrm{~cm}$ apart. Each plot was seeded with a precision vacuum planter calibrated to deliver 120 seeds per row $(240,000$ seeds $\mathrm{ha}^{-1}$ ). The experiments were planted 22 May 2003 and 21 May 2004. Nitrogen fertilizer was applied preplant at $157 \mathrm{~kg}$ ha ${ }^{1}$. Atrazine was applied at $2.2 \mathrm{~kg} \mathrm{ha}^{-1}$ immediately after planting, followed by an application of quinclorac (3,7-dichloro-8-quinolinecarboxylic acid) and atrazine at $0.37 \mathrm{~kg} \mathrm{ha}^{-1}$ and $1.1 \mathrm{~kg} \mathrm{ha}^{-1}$, respectively approximately $14 \mathrm{~d}$ postemergence. Grasshoppers [Dissosteira carolina (Linnaeus)] were controlled by application of chloropyrifos [phosphorodithioic acid, O,O-diethyl O-(3,5,6trichloro-2-pyridyl) ester] on 17 July 2003. In $20032.5 \mathrm{~cm}$ of supplemental irrigation was applied via overhead sprinklers on 24 July, 14 August, and 28 August, and $5 \mathrm{~cm}$ of supplemental irrigation was applied on 4 August and 7 August. In $20042.5 \mathrm{~cm}$ of supplemental irrigation was applied on 3, 12, and 19 August. Ten panicles per plot were bagged before anthesis to prevent outcrossing, hand-harvested on reaching maturity, threshed, and the grain stored at $7^{\circ} \mathrm{C}$ until laboratory analyses. The experimental design was a randomized complete block with four replications in each of the $2 \mathrm{yr}$.

Presence or absence of amylose was determined by staining with iodine as described in Pedersen et al. (2004). Presence or absence of the GBSS protein was determined using sodium dodecyl sulfate polyacrylamide gel electrophoresis (SDSPAGE) as described in Gaines et al. (2000). For amylose and GBSS classification, grain from two replicates from 2003 was tested. Entries were grouped into the following phenotypes: wild-type, waxy-GBSS+, waxy-GBSS-. Entries comprised of a mixture of wild-type and waxy grains were excluded from further analyses.

\section{Starch Extraction}

Three grams of seed per plot was cleaned by hand to remove broken seeds and foreign material, and then steeped in $10 \mathrm{~mL}$ of $1 \%$ sodium metabisulfite for $24 \mathrm{~h}$ at $45^{\circ} \mathrm{C}$ (Ji et al., 2004). The 
Table 1. Accession number, local name, and country of origin of lines previously reported to be waxy and photoperiod insensitive in the USDA-ARS sorghum germplasm collection, control varieties, and results of iodine test for amylose and sodium dodecyl sulfate polyacrylamide gel electrophoresis test for granule bound starch synthase (GBSS).

\begin{tabular}{|c|c|c|c|c|c|}
\hline Accession no. & Local name & Country of origin & Amylose present & GBSS present & Allele \\
\hline PI 23231 & Brown Kaoliang & China & no & yes & $w x^{b}$ \\
\hline PI 55123 & Hemaise & Sudan & no & no & $w x^{a}$ \\
\hline PI 76407 & North West Gold Kaoliang & China & no & no & $w x^{a}$ \\
\hline PI 82340 & Kaoliang-WX & Korea & no & no & $w x^{a}$ \\
\hline PI 87355 & Bomususu & Korea & no & no & $w x^{a}$ \\
\hline Pl 88004 & Susu zairai shu & Korea & no & no & $w x^{a}$ \\
\hline PI 173971 & Jawar & India & yes & yes & $W x$ \\
\hline PI 175316 & Mal Giunra & India & yes & yes & $W x$ \\
\hline PI 192876 & Katengu & Indonesia & no & no & $w x^{a}$ \\
\hline PI 217896 & 244 & Indonesia & mixed & yes & $?$ \\
\hline PI 217897 & 305 & Indonesia & no & yes & $w x^{b}$ \\
\hline PI 220636 & Nai-Shaker & Afghanistan & no & no & $w x^{a}$ \\
\hline PI 234456 & Unknown local name & Japan & no & no & $w x^{a}$ \\
\hline PI 246699 & IS 1024 & India & yes & yes & $W x$ \\
\hline PI 250230 & MN 4116 & Pakistan & yes & yes & $W x$ \\
\hline PI 455538 & ETS 3632 & Ethiopia & mixed & yes & $?$ \\
\hline PI 455543 & ETS 3634 & Ethiopia & no & no & $w x^{a}$ \\
\hline PI 547915 & Bai Ruan Gao Liang & China & yes & yes & $W x$ \\
\hline PI 548008 & Huang Ke Jiao & China & no & no & $w x^{a}$ \\
\hline PI 562758 & Basuto Red Q2-1-29 & USA & no & no & $w x^{a}$ \\
\hline PI 562768 & Purdue 81540 & USA & mixed & yes & $?$ \\
\hline PI 563015 & Kaura Mai Faran Kona & Nigeria & no & no & $w x^{a}$ \\
\hline PI 563068 & IS 8303 & USA & no & no & $w x^{a}$ \\
\hline PI 563395 & IS 10464 & Uganda & mixed & yes & $?$ \\
\hline PI 563402 & IS 10497 & USA & no & no & $w x^{a}$ \\
\hline PI 563576 & LV 129 & China & no & no & $w x^{a}$ \\
\hline PI 563611 & LR 390 & China & yes & yes & $W x$ \\
\hline PI 563612 & LR 395 & China & yes & yes & $W x$ \\
\hline PI 563670 & L 1999B-17 & China & no & yes & $w x^{b}$ \\
\hline PI 563671 & L 1999B-18 & China & no & yes & $w x^{b}$ \\
\hline PI 563672 & LR 2409 & China & yes & yes & $W x$ \\
\hline PI 565116 & SDS 1412 & Zimbabwe & yes & yes & $W x$ \\
\hline PI 567796 & Pyungchang local & South Korea & no & no & $w x^{a}$ \\
\hline PI 567799 & Pyungchang local & South Korea & mixed & yes & $?$ \\
\hline PI 567803 & Yungju local & South Korea & no & no & $w x^{a}$ \\
\hline PI 567809 & Unknown local name & South Korea & no & no & $w x^{a}$ \\
\hline PI 567810 & Unknown local name & South Korea & mixed & no & $?$ \\
\hline PI 567811 & Unknown local name & South Korea & no & no & $w x^{a}$ \\
\hline PI 567910 & Bai Liu Zi (Fu Yang) & China & yes & yes & $W x$ \\
\hline PI 567913 & Bai She Yan (Sui Zhong) & China & yes & yes & $W x$ \\
\hline PI 567931 & Da Shan Dong (Wen Shui) & China & yes & yes & $W x$ \\
\hline PI 567939 & Gao Liang & China & yes & yes & $W x$ \\
\hline PI 567965 & Da E Huang & China & mixed & yes & \\
\hline PI 568012 & Niu Xin & China & yes & yes & $W x$ \\
\hline PI 568031 & Da Luo Chui & China & mixed & yes & $?$ \\
\hline PI 585348 & IS 24522 & Lebanon & no seed & no seed & $?$ \\
\hline PI 586448 & Cody & Hungary & no & no & $w x^{a}$ \\
\hline PI 586454 & Leoti & Hungary & no & no & $w x^{a}$ \\
\hline PI 586524 & IS 27929 & China & no & no & $w x^{a}$ \\
\hline PI 586526 & IS 27931 & China & no & no & $w x^{a}$ \\
\hline PI 586529 & IS 27935 & China & no & no & $w x^{a}$ \\
\hline
\end{tabular}


Table 1. Continued.

\begin{tabular}{|c|c|c|c|c|c|}
\hline Accession no. & Local name & Country of origin & Amylose present & GBSS present & Allele \\
\hline PI 586532 & IS 27938 & China & mixed & no & $?$ \\
\hline \multirow[t]{3}{*}{ PI 591372} & IS 3244 & India & no seed & no seed & $?$ \\
\hline & \multirow[t]{2}{*}{ Ellis } & USA & no & no & $w x^{a}$ \\
\hline & & \multicolumn{2}{|l|}{ Wild-type controls } & & \\
\hline NSL 7433 & Dale & USA & yes & yes & $W x$ \\
\hline- & E35-1 & USA & yes & yes & $W x$ \\
\hline- & IS 2261 & USA & yes & yes & $W x$ \\
\hline- & Kansas Collier & USA & yes & yes & $W x$ \\
\hline PI 535783 & N98 & USA & yes & yes & $W x$ \\
\hline
\end{tabular}

seeds were then homogenized in $50 \mathrm{~mL}$ distilled water using a single speed Waring blender (Waring Laboratory, Torrington, $\mathrm{CT}$ ) and a $110-\mathrm{mL}$ minicontainer. This slurry was then filtered through four layers of cheesecloth and allowed to settle at $4^{\circ} \mathrm{C}$ for $1 \mathrm{~h}$. The starch was then layered onto $10 \mathrm{~mL}$ of $60 \%$ cesium chloride and centrifuged at $1643 \times g$ using a Beckman GS-6 swinging bucket centrifuge (Beckman Coulter Inc., Fullerton, CA) to separate the starch from impurities. The starch was then washed three times with $10 \mathrm{~mL}$ of water and allowed to dry overnight at $34^{\circ} \mathrm{C}$ (Beta et al., 2000). The dried starch was then placed in a moisture-controlled cabinet for $4 \mathrm{~d}$. Moisture content was determined by heating a portion of the sample to $140^{\circ} \mathrm{C}$ for $30 \mathrm{~min}$ and calculating the difference in mass before and after heating.

\section{Thermal Analyses}

Analyses of the starch gelatinization were made in triplicate for each sample using a Pyris Diamond DSC and Pyris v. 7 software (PerkinElmer, Norwalk, CT). Approximately $10 \mathrm{mg}$ dry starch for each sample was placed inside a high-pressure stainless steel pan (PN: 03190029, PerkinElmer, Norwalk, CT) along with $55 \propto 1$ autoclaved water to give a starch/water ratio of 1:5 (Sichina, 2000). The sample pans were then sealed and stored at room temperature overnight to allow starch to hydrate. During the experiment, samples were allowed to equilibrate at $40^{\circ} \mathrm{C}$ for $2 \mathrm{~min}$ before being heated to $120^{\circ} \mathrm{C}$ at $10^{\circ} \mathrm{C} \mathrm{min}^{-1}$. The DSC was calibrated with indium and an empty pan was used as a reference (Iturriaga et al., 2004). Pyris software (v. 7, PerkinElmer) was used to calculate gelatinization transition temperatures (onset, peak, and end), total heat of transition or

Table 2. Least square means of differential scanning calorimeter data for waxy-GBSS+, waxy-GBSS-, and wild-type sorghum grain.

\begin{tabular}{lccccc}
\hline & $\begin{array}{c}\text { Onset } \\
\text { temperature }\end{array}$ & $\begin{array}{c}\text { Peak } \\
\text { temperature }\end{array}$ & $\begin{array}{c}\text { End } \\
\text { temperature }\end{array}$ & $\begin{array}{c}\text { Enthalpy } \\
(\Delta \mathrm{H})\end{array}$ & $\begin{array}{c}\text { Peak } \\
\text { height }\end{array}$ \\
\cline { 3 - 4 } Waxy/GBSS- & $69.2 \mathrm{~b}^{\dagger}$ & $74.7 \mathrm{a}$ & $80.8 \mathrm{a}$ & $16.4 \mathrm{a}$ & $4.17 \mathrm{~b}$ \\
Waxy/GBSS+ & $70.1 \mathrm{a}$ & $74.7 \mathrm{a}$ & $80.3 \mathrm{~b}$ & $16.9 \mathrm{a}$ & $4.71 \mathrm{a}$ \\
Wild-type & $66.8 \mathrm{c}$ & $72.0 \mathrm{~b}$ & $77.6 \mathrm{c}$ & $15.3 \mathrm{~b}$ & $4.05 \mathrm{c}$ \\
\hline
\end{tabular}

${ }^{\dagger}$ Means in a column followed by the same letter are not significantly different at $P=0.05$. enthalpy, and the amount of heat required to initiate gelatinization (peak height).

\section{Statistical Analyses}

To contain costs, only two replications per year were initially analyzed using the DSC. After examination of the resulting data, the decision was made to limit analyses using the DSC to those two replications. The DSC data analysis for this paper was generated using the PROC MIXED procedure of SAS (SAS Institute, 2002-2003) with years and reps considered random. Phenotype and entries within phenotype were considered fixed. All reported means were generated using the LSMEANS function, and significance of differences between phenotypes was determined using a $t$ test, calculated by the DIFF function of PROC MIXED.

\section{RESULTS}

Of the 51 purported waxy accessions examined, 14 tested positive for presence of amylose and for presence of GBSS (Table 1). These accessions were considered to be wildtype lines misclassified by previous investigators as waxy. Another nine accessions were mixed for presence or absence of amylose-containing grain. Of the nine accessions mixed for the presence or absence of amylose-containing grain, one accession, PI 567810, tested negative for GBSS. Upon examination of the raw data, only one seed of 18 tested positive for amylose leading to speculation that a false positive or mechanical seed mixture may have been observed for amylose in PI 567810. Four of the 28 accessions confirmed to be waxy by negative iodine staining for amylose were shown to contain GBSS.

Mean gelatinization onset, peak, and end temperatures were significantly $(P=0.05)$ lower for wild-type than either of the two waxy genotypes (Table 2). Mean gelatinization onset temperature was slightly higher $(P=0.05)$ for waxy-GBSS+ genotypes than waxyGBSS- genotypes, while mean gelatinization end 
temperature was slightly higher $(P=0.05)$ for waxy-GBSSgenotypes than waxy-GBSS+ genotypes. Mean gelatinization peak temperature and mean enthalpy were equivalent $(P=0.05)$ for waxy-GBSS - genotypes and waxy-GBSS+ genotypes. For all five DSC traits measured, when examining individual accessions considerable variation was observed within each genotype group (Fig. 1-5).

\section{DISCUSSION}

Within this group of 51 purported waxy accessions, 27\% were wholly misclassified and $17 \%$ are previously undetected mixtures. It is our understanding that identification of waxy accessions in the U.S. sorghum collection has been accomplished primarily using visual examination of grain fracture patterns. Clearly, simple chemical tests such as iodine staining (Pedersen et al., 2004) are more reliable. Our experience in working with waxy sorghum also leads us to conclude that the inverse error, failure to identify lines with pure amylopectin, or waxy lines, can easily occur. Although not investigated in this research, it is likely that additional waxy lines could be identified within the U.S. sorghum collection by application of reliable screening procedures. This investigation also demonstrates, however, that SDS-PAGE evaluation of starch granule proteins alone would not correctly identify all

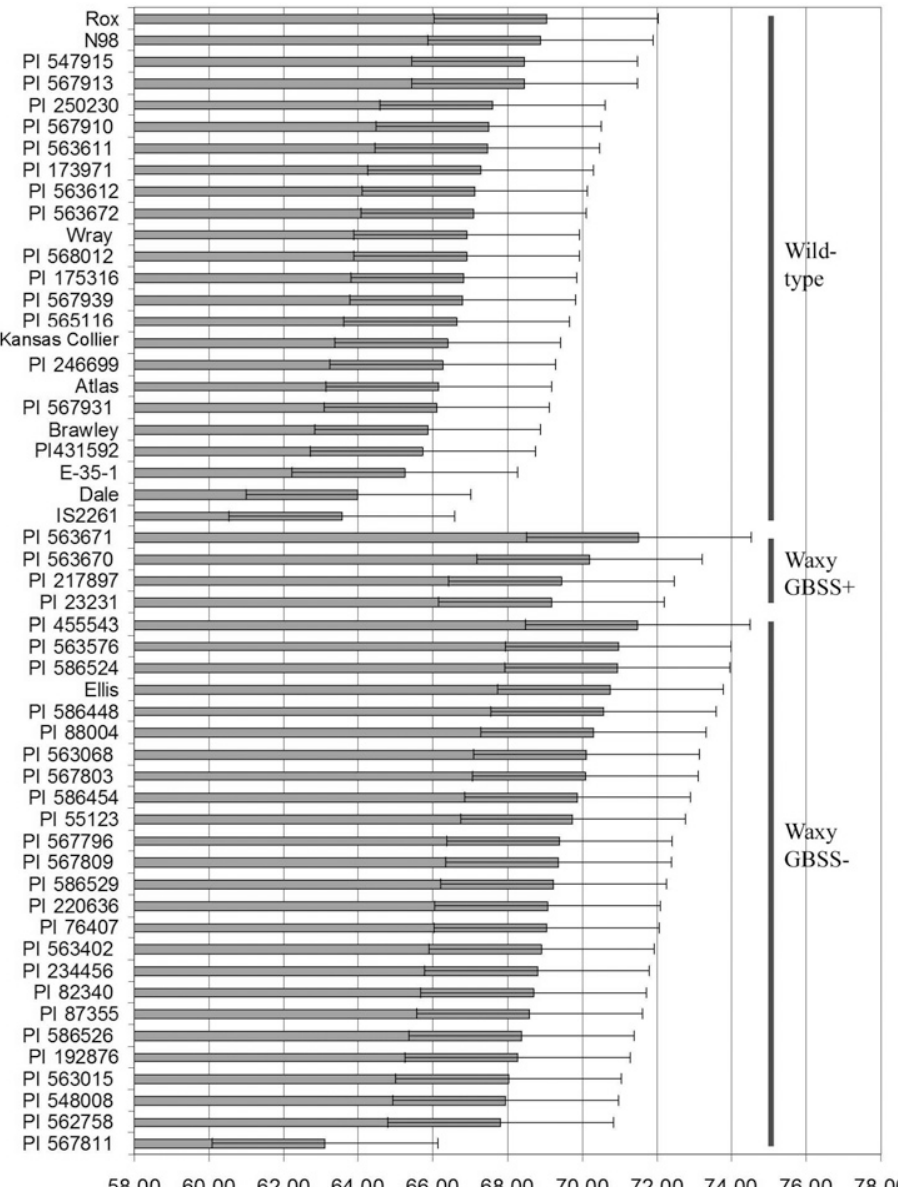

Figure 1. Least square means and standard errors for gelatinization onset temperature $\left({ }^{\circ} \mathrm{C}\right)$. GBSS, granule bound starch synthase. waxy sorghum accessions. Several GBSS+, but amylosefree lines, were detected.

Before this research, the BTxARG-1 and B9307 (an experimental line from Texas A\&M University) were known to be waxy yet still possess GBSS (Pedersen et al., 2005). Seed of both lines was found to contain evidently nonfunctional GBSS. The exact pedigree of B9307 is unknown, but is thought to be similar to BTxAGR-1 (William L. Rooney, personal communication, 2002). The discovery of GBSS in PI 217897 from Indonesia and PI 23231, PI 563670, and PI 563671 from China more than doubles the number of lines known to possess the $w x^{b}$ allele. The presence of $w x^{b}$ in lines from China and Indonesia would indicate either two independent mutations or germplasm flow across a fairly wide distance.

The observed gelatinization temperatures of both waxy classes were similar to those reported for waxy sorghum by Choi et al. (2004). The observed differences between the two waxy genotypic classes in both onset and end temperatures suggests a possible role of GBSS in maintenance or alteration of starch structure, as proposed by previous investigators (Hamaker and Griffin, 1993; Hamaker et al., 1991). Han and Hamaker (2002) further demonstrated a role of GBSS in maintaining the structure of starch "ghosts" or gelatinized starch gran-

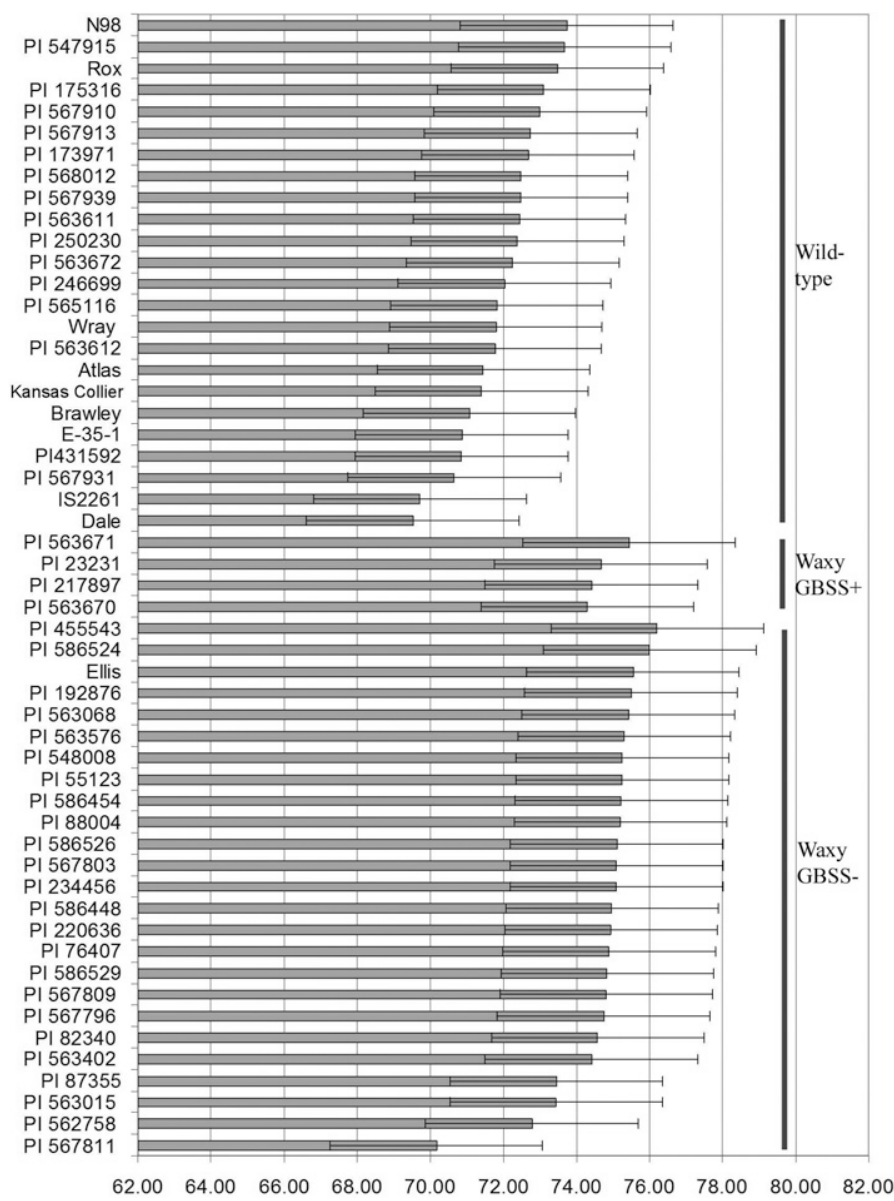

Figure 2. Least square means and standard errors for gelatinization peak temperature $\left({ }^{\circ} \mathrm{C}\right)$. GBSS, granule bound starch synthase. 


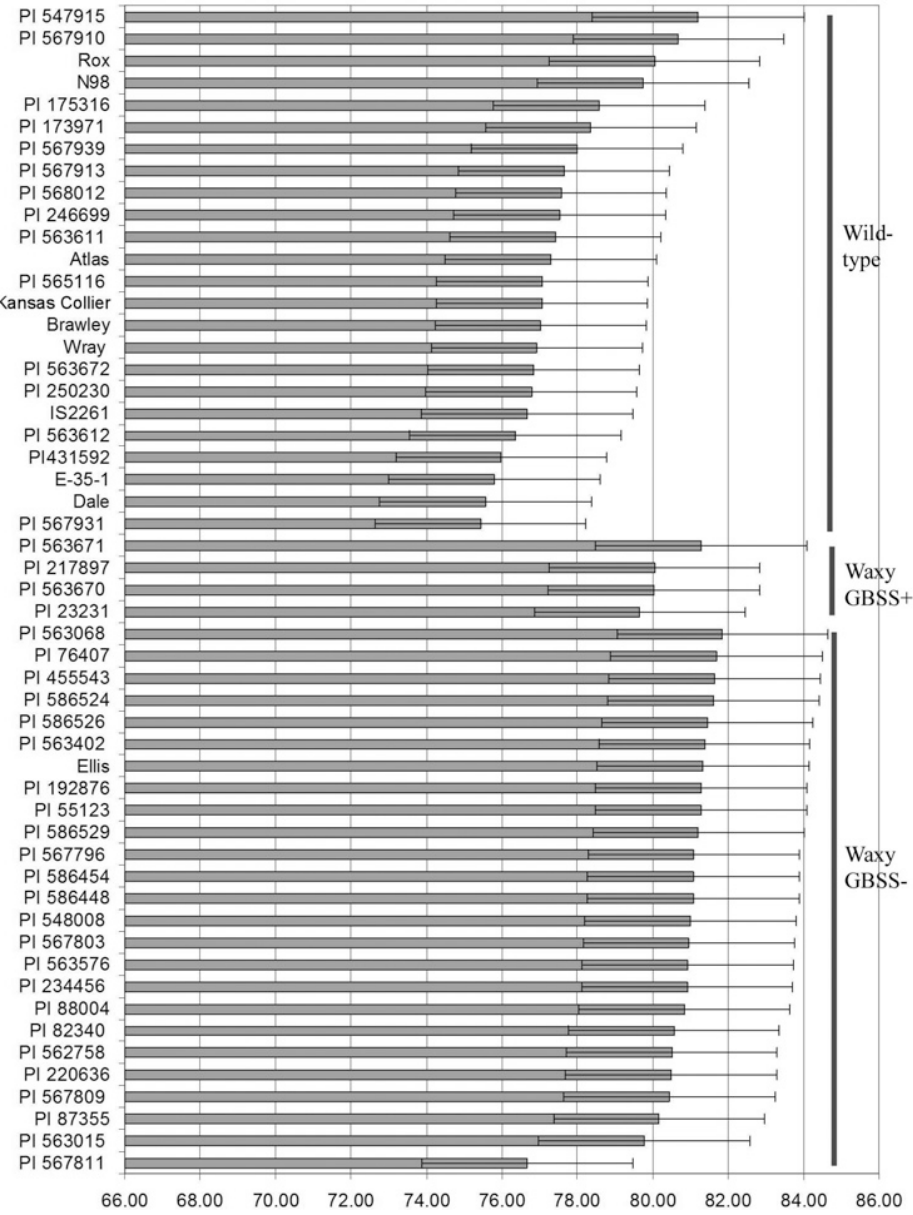

Figure 3. Least square means and standard errors for gelatinization end temperature $\left({ }^{\circ} \mathrm{C}\right)$. GBSS, granule bound starch synthase.

ule remnants. van de Wal et al. (1998) hypothesized that during the process of starch granule synthesis, GBSS becomes tightly and perhaps covalently attached to the amylopectin matrix. In sorghum lines carrying the $w x^{b}$ allele, GBSS is present, but not functional. It also is not extracted with SDS solutions and is only liberated from the starch granule after boiling. Even though it evidently lacks enzymatic activity, GBSS in $w x^{b}$ waxy sorghum may bind tightly enough to amylopectin to alter its melting parameters. There may be, therefore, microstructural differences between the waxy starches of different sources in sorghum, and these differences might result in different functional or digestive properties.

Significant genetic variation was observed within genotypic classes, especially for gelatinization enthalpy (Fig. 4), suggesting either influence of additional modifier genes affecting sorghum starch structure, or microenvironmental effects. Jennings et al. (2002) found harvest date to have a significant effect on DSC-determined enthalpies of maize starches, with later harvested materials requiring more energy for transition. Differences in days to maturity amongst this diverse sorghum germplasm collection also might have influenced starch granule melting properties. Standard errors for DCS

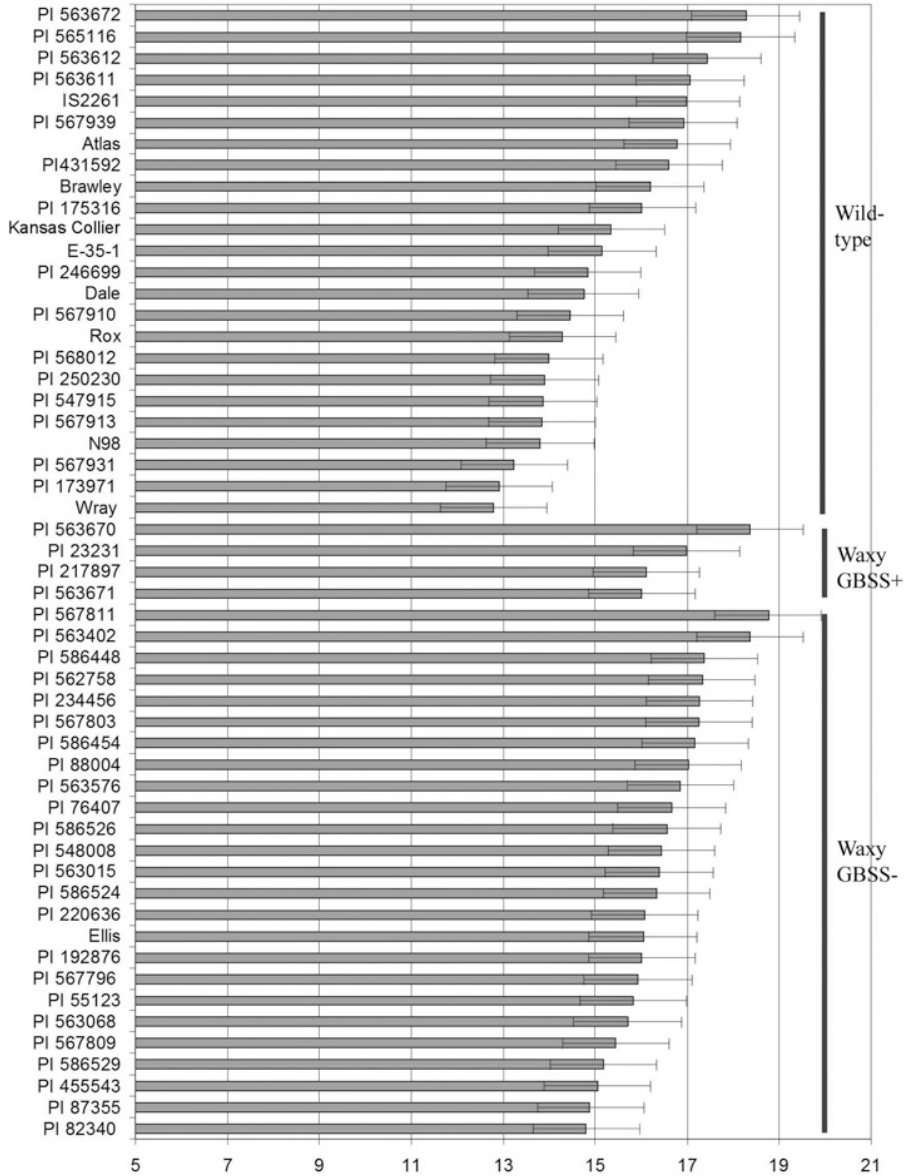

Figure 4. Least square means and standard errors for gelatinization enthalpy $\left(\mathrm{J} \mathrm{g}^{-1}\right)$. GBSS, granule bound starch synthase.

values were larger than generally reported. Environmental effects of two production years plus micro-environmental effects of field location would be expected result in larger standard errors than in studies that do not include these sources of variation.

In North America, the commercial starch industry primarily relies on maize, utilizing wild-type and various mutant forms including high-amylose and waxy. In agroecological terms, sorghum is an attractive alternative to maize. Sorghum may be produced in most environments used to cultivate maize, but sorghum requires far less water. Under periods of prolonged drought, sorghum provides producers an attractive alternative. The observed variation in starch properties reported herein, both within wild-type and waxy classes, suggests the availability of sorghum accessions useful in diverse starch products. Presently, sorghum primarily is used as a feed grain for livestock. However, worldwide, sorghum is used to produce unleavened breads, alcoholic beverages, or in the manufacture of building materials. Finally, the detected differences in starch gelatinization properties of GBSS+ and GBSSwaxy genotypes will aid in further elucidation of the role of granule-bound proteins in starch granule formation and structure. 


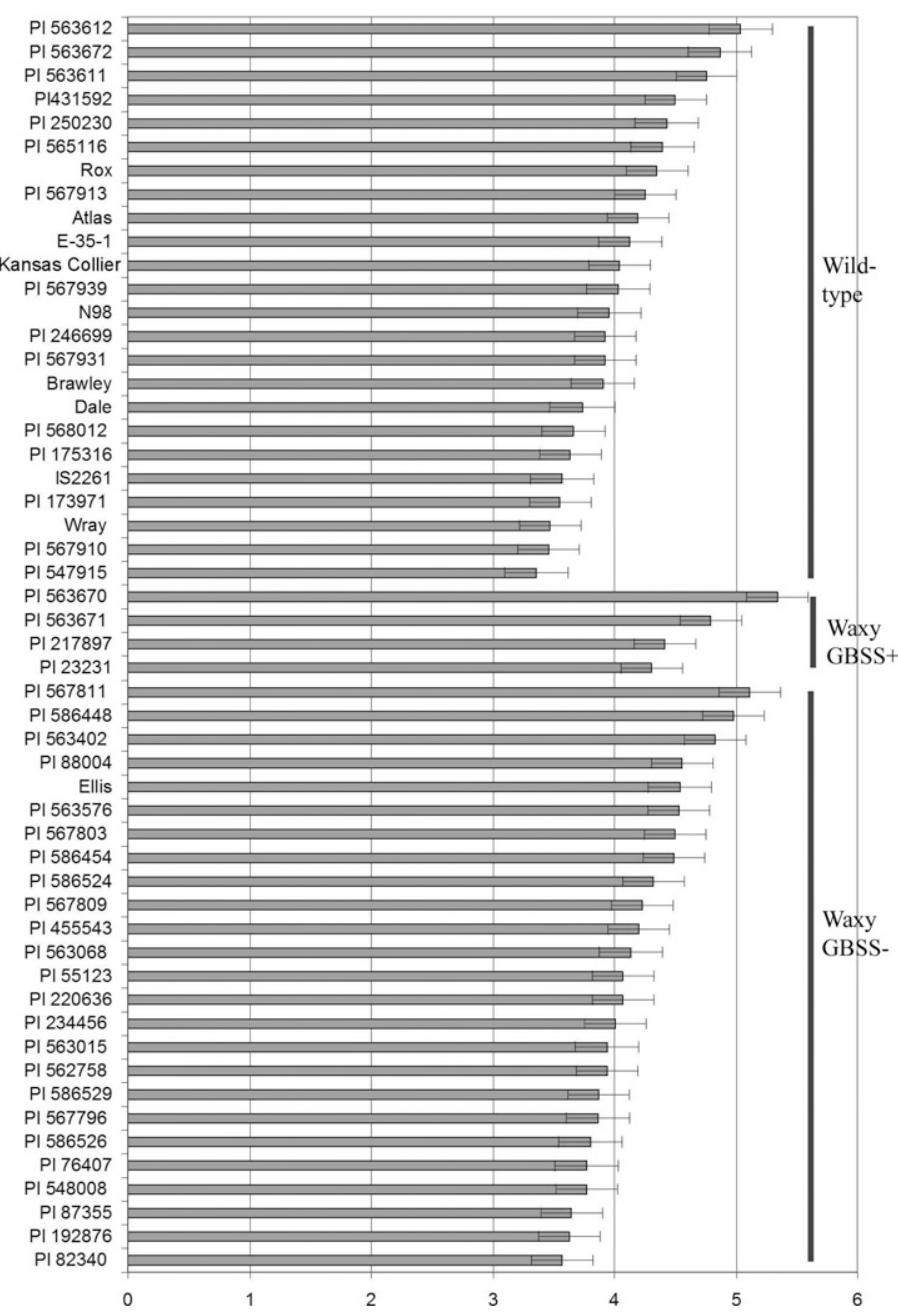

Figure 5. Least square means and standard errors for peak height $(\mathrm{mW})$. GBSS, granule bound starch synthase.

\section{References}

Beta, T., H. Corke, L.W. Rooney, and J.R.N. Taylor. 2000. Starch properties as affected by sorghum grain chemistry. J. Sci. Food Agric. 81:245-251.

Choi, H., W. Kim, and M. Shin. 2004. Properties of Korean amaranth starch compared to waxy millet and waxy sorghum starches. Starke 56:469-477.

Gaines, C.S., M.Ö. Raeker, M. Tilley, P.L. Finney, J.D. Wilson, D.B. Bechtel, R.J. Martin, P.A. Seib, G.L. Lookhart, and T. Donelson. 2000. Associations of starch gel hardness, granule size, waxy allelic expression, thermal pasting, milling quality, and kernel texture of 12 soft wheat cultivars. Cereal Chem. 77:163-168.

Hamaker, B.R., and V.K. Griffin. 1993. Effect of disulfide bond containing protein on rice starch gelatinization and pasting. Cereal Chem. 70:377-380.

Hamaker, B.R., V.K. Griffin, and K.A.K. Moldenhauer. 1991. Potential influence of a starch granule-associated protein on cooked rice stickiness. J. Food Sci. 56:1327-1329.

Han, X.-Z., and B.R. Hamaker. 2002. Association of starch granule proteins with starch ghosts and remnants revealed by confocal laser scanning microscopy. Cereal Chem. 79:892-896.

Iturriaga, L., B. Lopez, and M. Anon. 2004. Thermal and physiochemical characterization of seven argentine rice flours and starches. Food Res. Int. 37:439-447.

Jane, J., Y.Y. Chen, L.F. Lee, A.E. McPherson, K.W. Wong, M. Radosavljevic, and T. Kasemsuwan. 1999. Effects of amylopectin branch chain length and amylose content on the gelatinization and pasting properties of starch. Cereal Chem. 76:629-673.

Jennings, S.D., D.J. Meyers, L.A. Johnson, and L.M. Pollak. 2002. Effects of maturity on corn starch properties. Cereal Chem. 79:703-706.

Ji, Y., K. Seetharaman, and P.J. White. 2004. Optimizing a smallscale corn starch extraction method for use in the lab. Cereal Chem. 81:55-58.

Karper, R.E. 1933. Inheritance of waxy endosperm in sorghum. J. Hered. 24:257-262.

Lund, D. 1984. Influence of time, temperature, moisture, ingredients, and processing conditions on starch gelatinization. CRC Crit. Rev. Food Sci. Nutr. 20:249-273.

Martin, C., and A.M. Smith. 1995. Starch biosynthesis. Plant Cell 7:971-985.

Pedersen, J.F., S.R. Bean, D.L. Funnell, and R.A. Graybosch. 2004. Rapid iodine staining techniques for identifying the waxy phenotype in sorghum grain and waxy genotype in sorghum pollen. Crop Sci. 44:764-767.

Pedersen, J.F., S.R. Bean, R.A. Graybosch, S.H. Park, and M. Tilley. 2005. Characterization of waxy grain sorghum lines in relation to granule-bound starch synthase. Euphytica 144:151-156.

Sanders, E.B., D.B. Thompson, and C.D. Boyer. 1990. Thermal behavior during gelatinization and amylopectin fine structure for selected maize genotypes as expressed in four inbred lines. Cereal Chem. 67:594-602.

SAS Institute. 2002-2003. SAS/STAT software, version 9.1 of the SAS system for XP Pro. SAS Inst., Cary, NC.

Scott, M.P., and S.A. Duvick. 2005. Identification of QTL controlling thermal properties of maize starch. Cereal Chem. 82:546-553.

Sichina, W.J. 2000. Use of DSC for the characterization of starches. PerkinElmer Application Note PETech-04. PerkinElmer Instruments, Norwalk, CT.

Takahiro, N., Y. Nishiba, T. Sato, and I. Suda. 2003. Properties of starches from several low-amylose rice cultivars. Cereal Chem. 80:193-197.

van de Wal, M., C. D’Hulst, J.-P. Vincken, A. Buléon, R. Visser, and S. Ball. 1998. Amylose is synthesized in vitro by extension of and cleavage from amylopectin. J. Biol. Chem. 273:22232-22240.

White, P., I. Abbas, L. Pollak, and L. Johnson. 1990. Intra- and interpopulation variability of thermal properties of maize. Cereal Chem. 67:70-73. 